\title{
Health-related Quality of Life in Metastatic and Adjuvant Breast Cancer Patients
}

\section{Gesundheitsbezogene Lebensqualität bei Brustkrebspatientinnen in der metastasierten oder adjuvanten Situation}

Authors

Affiliations
M. Wallwiener ${ }^{1}$, E. Simoes ${ }^{2,3,4}$, A. N. Sokolov ${ }^{2,3}$, S. Y. Brucker ${ }^{2,3}$, P. A. Fasching ${ }^{5}$, J. Graf ${ }^{2,3,6}$

The affiliations are listed at the end of the article.

Key words
breast cancer
metastatic and adjuvant
setting
PRO
HRQL
EORTC QLQ-C30
Schlüsselwörter
Brustkrebs
metastasierte oder adjuvante
Situation
PRO
gesundheitsbezogene
Lebensqualität
EORTC QLQ-C30

Deutsche Version unter: http://dx.doi.org/ $10.1055 / \mathrm{s}-0042-113188$

\section{Abstract \\ $\nabla$}

Introduction: When cancer patients have advanced disease and a primary cure is no longer possible, the focus is on maintaining the patient's quality of life. Recent therapeutic advances in breast cancer treatment mean that even patients with metastatic disease can remain stable for long periods of time. The aim of this study was to look at the health-related quality of life (HRQL) of these patients and compare it with data for the general population and to show the differences in outcomes for different survey instruments used to measure quality of life.

Material and Methods: A total of 96 breast cancer patients with metastatic disesae or receiving adjuvant therapy were questioned about their quality of life. Patients were investigated using the established survey instruments EORTC QLQ-C30, EORTC QLQ-BR23, EQ-5D-5L and EQ VAS. All patients filled out questionnaires. Statistical analysis was done using MS Excel and SPSS.

Results: Although the questionnaires were completed at the same time, the different questionnaires showed significant differences with regard to the level of stress experienced by the patient. When the EQ VAS questionnaire was used, the patient's current state of health was assessed as significantly better than with the EORTC QLQ-C30. Overall, all aspects of patients' quality of life were found to be in need of optimization and HRQL of patients was significantly poorer in all areas compared to the reference population.

Conclusion: To improve the quality of life of patients with metastatic disease, it is necessary to continuously monitor the success of therapy. The choice of survey tools is highly relevant as assessments differ considerably depending on the choice of questionnaire.

\section{Zusammenfassung \\ $\nabla$}

Einleitung: Liegt bei einer Krebserkrankung bereits ein fortgeschrittenes Stadium vor und ist somit eine primäre Heilung nicht mehr möglich, steht die Erhaltung der Lebensqualität im Fokus. Gerade beim Mammakarzinom sind durch die verbesserten neuen Therapien auch im metastasierten Stadium noch längere stabile Verläufe möglich. Ziel dieser Studie war es deshalb, einerseits die Lebensqualität der Patientinnen durch einen Vergleich mit Daten der Gesamtbevölkerung darzustellen und andererseits Unterschiede zwischen den verschiedenen Erhebungsinstrumenten aufzuzeigen.

Material und Methoden: Insgesamt wurden $\mathrm{n}=96$ Brustkrebspatientinnen in metastasierter oder adjuvanter Situation hinsichtlich ihrer Lebensqualität befragt. Dabei kamen die etablierten Erhebungsinstrumente EORTC QLQ-C30, EORTC QLQ-BR23, EQ-5D-5L und EQ-VAS zum Einsatz, wobei alle Patientinnen alle Bögen ausfüllten. Die statistische Analyse erfolgte mittels MS Excel und SPSS.

Ergebnisse: Obwohl die Bögen zum gleichen Zeitpunkt ausgefüllt wurden, zeigten sich deutliche Unterschiede im Belastungsniveau in Abhängigkeit zum angewandten Bogen. Beim Einsatz des EQ VAS wurde der aktuelle Gesundheitsstatus signifikant besser beurteilt als beim EORTC QLQ-C30. Insgesamt gestaltete sich die Lebensqualität der Patientinnen in allen Dimensionen als optimierungsbedürftig und war in allen Bereichen signifikant schlechter als in der Referenzbevölkerung.

Schlussfolgerung: Um die Lebensqualität von metastasierten Patientinnen zu verbessern, ergibt sich die die Notwendigkeit des beständigen Therapieerfolg-Monitorings. Von Relevanz ist die Wahl des Erhebungsinstruments, da in Abhängigkeit vom Erhebungsinstrument unterschiedliche Werte ermittelt wurden. 


\section{Introduction}

$\nabla$

Breast cancer is one of the most common malignant diseases; with an incidence of $32 \%$ of all new cancer diagnoses it is the most common cancer in women. At present the lifetime risk of developing this disease is $12.9 \%$ [1]. The current incidence in Germany (2016) is predicted to be 65500 cases annually [2]; the ageadjusted incidence rate in 2012 was 117 cases per 100000 population and year [3]. Mortality has dropped significantly in recent years following a number of different therapeutic and diagnostic advances [4]. Age-adjusted mortality in Germany in 2010 was 23.9 cases per 100000 population and year; around 18000 patients die annually from breast cancer in Germany [3]. The (relative) mean 5-year survival rate irrespective of tumor status, stage and degree of metastasis is estimated to be $81 \%$, and relative survival rates for patients with early-stage disease are more than $90 \%$ [2,4-8]. Early menarche, childlessness, older age at first pregnancy, late menopause, hormone replacement therapies, estrogen and progestin-based ovulation inhibitors, lack of exercise, overweight and alcohol abuse are all important factors in the etiology of breast cancer [9]. Around 5-10\% of breast cancer cases are genetically determined [10]. Women with a mutation of the BRCA-1 gene have a lifetime risk of $57 \%$; the lifetime risk for women with a mutation of the BRCA-2 gene is 49\% [11]. While early-stage breast cancer is associated with high survival rates and often with high cure rates, the prognosis for patients with metastatic disease is significantly poorer. Often these patients can only be treated palliatively, and the goal is then to prolong life while trying to ensure that patients do not suffer tumor-related symptoms and are able to enjoy as good a quality of life as possible [12-14]. The mean life expectancy for women with breast cancer and metastatic disease is 18-33 months; the median progression-free survival is between 13.5 and 17 months $[15,16]$. Currently, the relative 5-year survival rate is significantly lower than 50\% [15]; the relative 10-year survival rate for patients with bone metastasis is reported to be $35 \%[17,18]$.

As medical therapies become increasingly personalized, patients' health-related quality of life (HRQL) is an important indicator of the efficacy of the therapeutic intervention, particularly in patients with chronic disease. The term "health-related quality of life" is a multidimensional construct which covers physical, psychological and social dimensions. Health-related quality of life is thus the subjective perception of the patient's state of health, which can be surveyed without requiring the interpretation of the treating physician (Patient Reported Outcomes, PRO) [19, 20]. The survey instruments usually consist of validated questionnaires, and scientists differentiate between generic (e.g. SF36) and specific (e.g. EORTC QLQ-C30) instruments used to measure outcomes. The latter are often used to assess cancer therapies and investigate patients with chronic disease [21]. The validity of the indicator has been confirmed in different studies in which patients with chronic disease rated their quality of life as significantly lower [22-24]. Health-related quality of life is a very important aspect of care for tumor patients, as survival rates and times for many types of cancer have increased due to medical advances, particularly in the fields of molecular biology and genetics. When evaluating the efficacy of therapeutic interventions, the Federal Joint Committee (Gemeinsamer Bundesausschuss, G-BA) no longer bases its assessment only on surival times but also explicitly includes patient-relevant endpoints which should describe "how the patient feels, to what extent she can perform functions and carry out activities and survive them" $[25,26]$.
The health-related quality of life of breast cancer patients has been investigated for many years $[27,28]$; it is particularly important for patients with metastatic disease as the primary goal of therapy for these patients is to provide them with the best possible quality of life during their remaining lifespan [12-14]. Adjuvant therapy can also lead to a significant deterioration in patients' quality of life [29]. A number of studies have investigated the quality of life of breast cancer patients, usually using the EORTC QLQ-C30 questionnaire, to determine the effectiveness of different (chemo-)therapeutic interventions or to compare them [30-32]. However, not many studies have looked at the quality of life and state of health of patients with metastatic disease or receiving adjuvant treatment and compared these findings with an age-adjusted cohort of the general population. Such comparisons are necessary to recognize whether and to what extent patients are free of symptoms. What has also been lacking is a systematic comparison of different survey instruments, as differences could potentially bias the validity of surveys. The aim of this study was to investigate patients' quality of life using a number of established questionnaires, to compare the results obtained using different questionnaires with one another and to analyze the findings with regard to the quality of life of the general population.

\section{Patients/Material and Methods \\ $\nabla$}

\section{Objectives and approach}

A cross-sectional study was carried out by the Department of Women's Health of the University Hospital Tübingen to investigate to what extent the findings on the HRQL of breast cancer patients with metastatic disease or receiving adjuvant treatment depends on the questionnaire used to survey the patients. All female breast cancer patients with metastatic disease or receiving adjuvant treatment who were older than 18 years, were receiving chemotherapy or targeted therapy, had a sufficient command of German and who were considered physically and psychologically stable enough by their treating physicians to answer the questions were included in the study. The questionnaires were administered during outpatient visits to the hospital and were completed under the supervision of a treating physician. Patients were requested to complete the questionnaires during the therapeutic intervention (chemotherapy and/or targeted therapy). The mean treatment time was two hours and patients were given the questionnaires at the start of the therapy session. The patients had been informed about the questionnaires beforehand and given their informed consent. The ethics committee approved the study prior to the start of the study (No.234/2014B01, Ethics Committee Tübingen). The treating physician of patients with metastatic disease was asked to provide information about the site of metastasis (osseous, pulmonary, hepatic, cerebral) but for reasons of data protection physicians were not asked about the tumor stage, extent of metastasis and the administered therapy (type of chemotherapy or targeted therapy) so as not to put the anonymization of patients at risk. Only patients who had previously undergone chemotherapy and who were receiving treatment again (chemotherapy and/or targeted therapy) at the time of the survey were included in the study. All patients knew what type of therapy (adjuvant vs. palliative treatment for metastasis) they were receiving. 


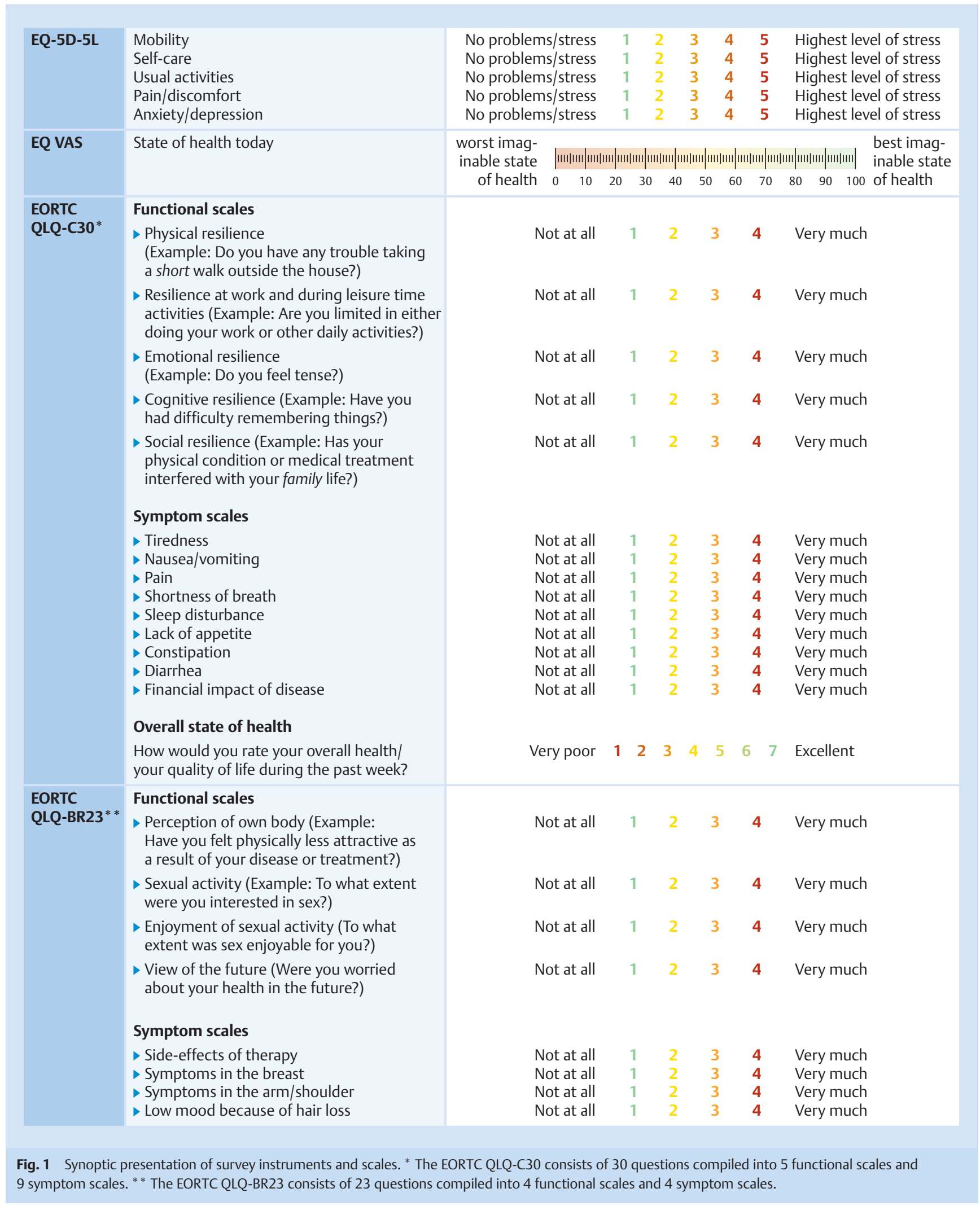

\section{Questionnaires}

The validated and scientifically established survey instruments EORTC QLQ-C30, EORTC QLQ-BR23, EQ-5D-5L and EQ VAS were used for the study ( $\bullet$ Fig. 1). The estalished disease-specific questionnaire EORTC QLQ-C30 consists of five functional scales and nine symptom scales which aim to provide a multidimensional assessment of the quality of life of patients based on 28 questions using a four point scale. Two additional questions are used to determine the state of health on a seven point Likert scale [33]. The side-effects of therapy and tumor-related symptoms in breast 
cancer patients were determined and recorded using the additional QLQ-BR23 module, which consists of 23 questions distributed across eight four point scales (in both questionnaires: $1=$ not at all; 4 = very much) [34]. The generic EQ-5D-5L questionnaire investigated the quality of life across five question categories using a five point scale and the EQ-VAS scale on which the overall state of health is marked by the patient in the form of a number $(0=$ worst imaginable state of health, 100 = best imaginable state of health) [35]. Patients were also asked for sociodemographic information (e.g. age, level of education).

\section{Method and statistical analysis}

After the data had been collected and entered, a frequency analysis was done with MS Excel 2010 and IBM SPSS 21 to obtain a descriptive analysis of the collected data. Analysis of the mean values of the EORTC questionnaires was done in accordance with the guidelines, where a score is calculated for each scale which can take any value between 0 and 100 [36]. While high scores in the five functional scales of the QLQ-C30 questionnaire indicate high functionality (and therefore a good quality of life), high scores in the symptom scales and most of the BR23 scales are classified as negative because a high score indicates high levels of symptoms. The evaluation of the EQ-5D-5L and EQ VAS questionnaires was done in accordance with the guidelines [37]. After describing the HRQL of the patient cohort, the items of the EORTC QLQ-C30 questionnaire were compared with scores for the general female population $(n=1309)$ as well as the scores of a cohort of women in the general population aged between 50-59 years $(n=272)$. The data for the general population were obtained from a representative cohort study of the German adult population [38]. Independent, two-tailed t-tests were done to identify differences between the investigated cohort of breast cancer patients and the comparison group. A two-tailed p-value of $<0.05$ was considered statistically significant for all analyses $(\alpha=0.05)$. In all calculations it was assumed that data were normally distributed (Shapiro-Wilk test). Independent, two-tailed t-tests were also carried out to identify differences between patients with metastatic disease and patients receiving adjuvant therapy. Because of the limited number of cases, it was not possible to carry out valid evaluations for individual sites of metastasis in the subcohort of patients with metastatic disease. Excel was used to create the graphs. For the box plot, the overall state of health compiled using the EORTC QLQ-C30 questionnaire was compared with the results obtained with the EQ VAS questionnaire.

\section{Results}

$\nabla$

The survey was carried out from July to November 2015; the participation rate was $80 \%$. A total of $65(68 \%)$ patients had metastatic disease, while 31 (32\%) patients were receiving adjuvant therapy. The two patient cohorts were grouped together for statistical analysis as there were no significant differences in healthrelated quality of life between the two groups (cf. $\square$ Table 2). A total of 96 patients (mean age: 57 years) with the appropriate diagnosis treated at the University Gynecological Hospital of Tübingen were surveyed by questionnaire. As the survey consisted of several different questionnaires, not all of the patients completed all sections, with some of the questionnaires at the back of the pack remaining incomplete; the result was that only 74 of the EORTC QLQ-C30 questionnaires could be included in the statistical analysis.
Table 1 Sociodemographic variables of the patient cohort.

\begin{tabular}{|c|c|}
\hline Sociodemographic variable & Size \\
\hline \multicolumn{2}{|l|}{ Age } \\
\hline Mean (median [25\% quantile, $75 \%$ quantile]) & $56.68(54[50 ; 66])$ \\
\hline - Standard deviation (range (minimum; maximum)) & $12.38(65[20 ; 85])$ \\
\hline \multicolumn{2}{|l|}{ Civil status } \\
\hline Married & $n=76(79 \%)$ \\
\hline - Married but living apart & $n=2(2 \%)$ \\
\hline Single & $\mathrm{n}=3(3 \%)$ \\
\hline Divorced & $n=4(4 \%)$ \\
\hline Widowed & $n=4(4 \%)$ \\
\hline Not specified (valid term) & $n=6(6 \%)$ \\
\hline \multicolumn{2}{|l|}{ Children } \\
\hline Y Yes & $n=69(72 \%)$ \\
\hline No & $\mathrm{n}=17(18 \%)$ \\
\hline Not specified & $\mathrm{n}=10(10 \%)$ \\
\hline \multicolumn{2}{|l|}{ Highest level of education achieved } \\
\hline - Left school without a qualification $(=1)$ & $\mathrm{n}=1(1 \%)$ \\
\hline $\begin{array}{l}\text { - Completed primary school or junior high school } \\
(=2)\end{array}$ & $\mathrm{n}=31(32 \%)$ \\
\hline High school diploma $(=3)$ & $\mathrm{n}=28((29 \%)$ \\
\hline - Technical college entrance qualification (=4) & $n=15(16 \%)$ \\
\hline University entrance diploma (=5) & $n=13(14 \%)$ \\
\hline Not specified & $\mathrm{n}=8(8 \%)$ \\
\hline \multicolumn{2}{|l|}{ Currently working } \\
\hline Yes, full time & $\mathrm{n}=11(12 \%)$ \\
\hline Yes, part time & $\mathrm{n}=31(32 \%)$ \\
\hline No & $n=43(45 \%)$ \\
\hline Not specified & $\mathrm{n}=11(11 \%)$ \\
\hline \multicolumn{2}{|l|}{ Disease status/therapy status } \\
\hline Metastatic disease & $n=65(68 \%)$ \\
\hline \multicolumn{2}{|l|}{ Site of metastasis } \\
\hline Osseous & $n=49(75 \%)$ \\
\hline Pulmonary & $n=26(40 \%)$ \\
\hline Hepatic & $n=17(26 \%)$ \\
\hline - Cerebral & $n=3(5 \%)$ \\
\hline$>1$ site of metastasis & $n=28(43 \%)$ \\
\hline Adjuvant & $\mathrm{n}=31(32 \%)$ \\
\hline
\end{tabular}

\section{Sociodemographic variables}

- Table 1 shows the sociodemographic variables of the patient cohort. The mean patient age was 56.68 years (age range: $20-85$ years). $38 \%$ of patients were in the cohort of patients aged between 50 and 59 years; the $25 \%$ and $75 \%$ age quantiles were 50 and 66 years (median: 54). 79\% of patients stated that they were married; two thirds of patients had children. $30 \%$ of patients were well educated (technical college entrance qualification or university entrance diploma); just under half were working despite disease (or at least working part-time). Around two thirds of patients had metastatic disease. The most common metastases in patients with metastatic disease were osseous or pulmonary; just under half of patients with metastatic disease had metastases in several different locations.

\section{Health-related quality of life and state of health of the Tübingen cohort}

- Fig. 2 shows the results for the EQ-5D-5L questionnaire. It is evident that patients experienced moderate stress levels particularly in the dimensions "performing usual activites", "pain/discomfort" and "anxiety/depression", while the reported stress levels for the aspects "mobility" and "self-care" were quite low. $42 \%$ of surveyed patients reported that they experienced slight to 


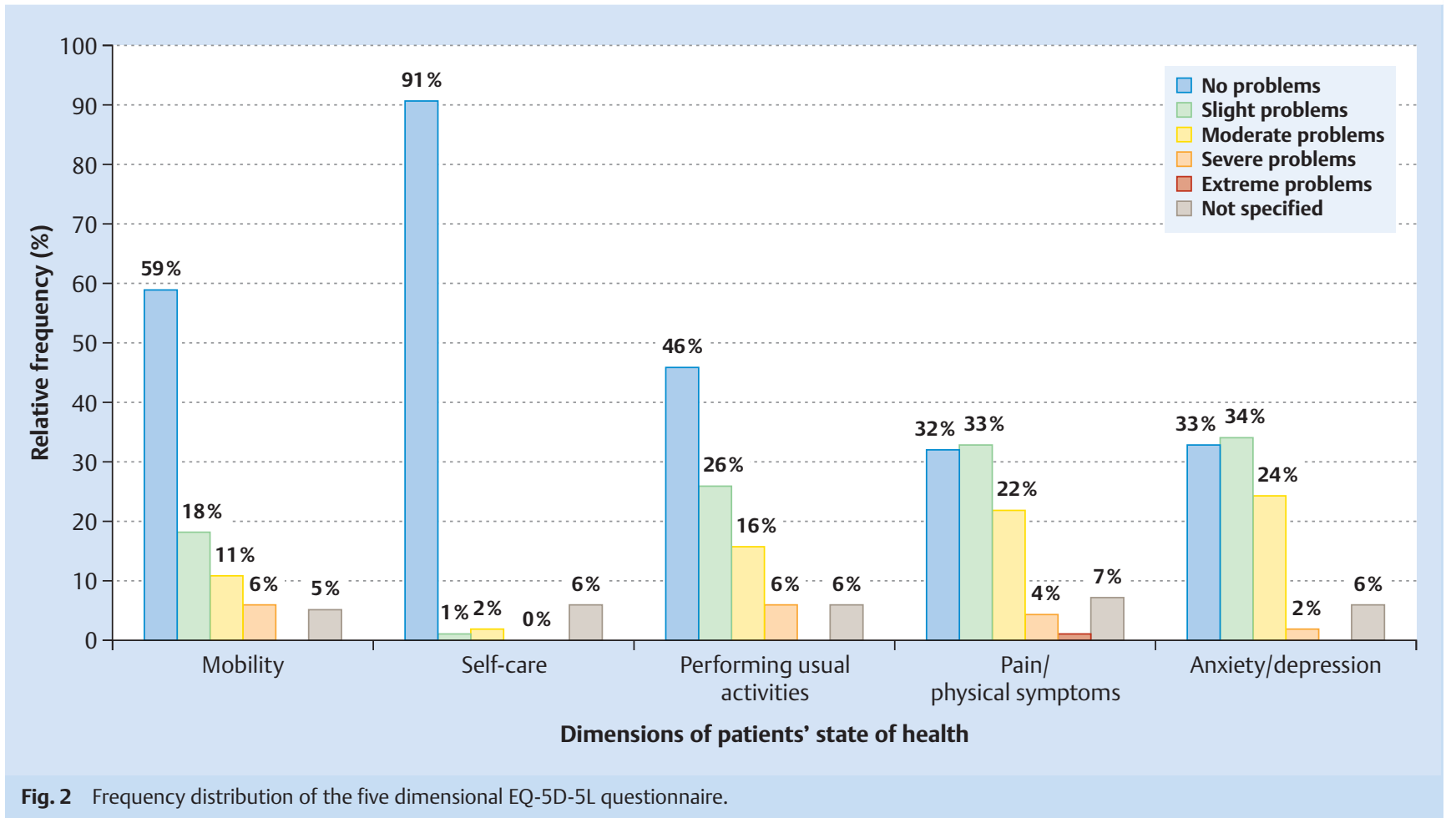

moderate problems in their daily activities, 55\% reported that they suffered light to moderate pain, and only $4 \%$ reported great pain. When questioned about "anxiety/depression”, 58\% stated that they felt light to moderate stress. Less than half of patients reported not experiencing any stress with regard to carrying out their usual activities (46\%), pain (32\%) or low mood (33\%); $59 \%$ of patients reported not experiencing any stress with regard to mobility, and $91 \%$ had no problems with self-care. Disease- or therapy-related stress varied in intensity depending on the surveyed dimension.

- Table 2 shows the survey results for the EORTC QLQ-C30 questionnaire and the BR23 breast module. Of the five functional scales of the QLQ-C30 questionnaire, the biggest constraints on patients were reported to occur at work and during leisure hours where the mean score was just 59.4, followed by social (61.4), emotional (63.6), physical (72.9) and cognitive resilience (75.4). In the QLQ-C30 symptom scales the stress levels were significantly higher and were particularly high for the symptoms “tiredness" (44.4), "sleep disturbance” (39.8), "pain” (32.3) and "shortness of breath" (27.7) and even slightly higher for the variables "diarrhea" (20.6) and "lack of appetite" (18.7). Only the symptom "nausea/vomiting" stayed relatively unchanged (7). The mean value for overall state of health as determined by the EORTC questionnaire was 58.2, with 100 as the score for the highest level of health. When analysing the results of the breast module, the score of 69.4 for "perception of own body" was particularly unfavorable. The degree of anxiety about their future state of health was also high with a score of 44.9. In the BR23 symptom scales high levels of stress were recorded for "side-effects of therapy" and "loss of hair".

What was most notable was that the different aspects of quality of life were portrayed differently depending on the scaling of the questionnaire ( Fig. 3). The differences between the current state of health as determined by the EQ VAS questionnaire (mean: 64.7; median: 70.0) and by the EORTC QLQ-C30 questionnaire (mean: 58.2; median: 58.3 ) were statistically significant $(\mathrm{p}=0.0323)$.

\section{Health-related quality of life of the cohort compared to the general population}

The EORTC questionnaire highlighted the extent of problems and restrictions in patients' health-related quality of life by comparing the results of a cohort of breast cancer patients with those of an average female population and those of a cohort of women aged 50-59 years who were chosen as a second reference collective because of the mean age of the breast cancer cohort of 56.7 years [38]. The mean of the five functional scales for the cohort of breast cancer patients was 23.7 points worse than that of the average female population (and breast cancer patients scored 24.5 points lower than the reference group of 50-59-year-old women). The most significant health-related restriction was found with regard to social resilience ( -31.9 and -32.2 points, respectively) and for resilience at work and during leisure time ( -30.5 and -32.5 , respectively). The differences between the cohort of breast cancer patients and the average female population and between the cohort of breast cancer patients and the female reference population of the same age were both statistically highly significant ( Table 3 ). When the symptom scales were evaulated, the quality of life of breast cancer patients was poorer across all dimensions of the scales and the differences were highly significant. On average, the stress score for the breast cancer patients was 17.1 points higher compared to the general population and 17.5 points higher compared to the reference group aged 50-59 years. The greatest differences were found for the symptoms "tiredness" ( +28 and +28.8 , respectively), "sleep disturbance" (+26.8 and +24 , respectively) and "shortness of 


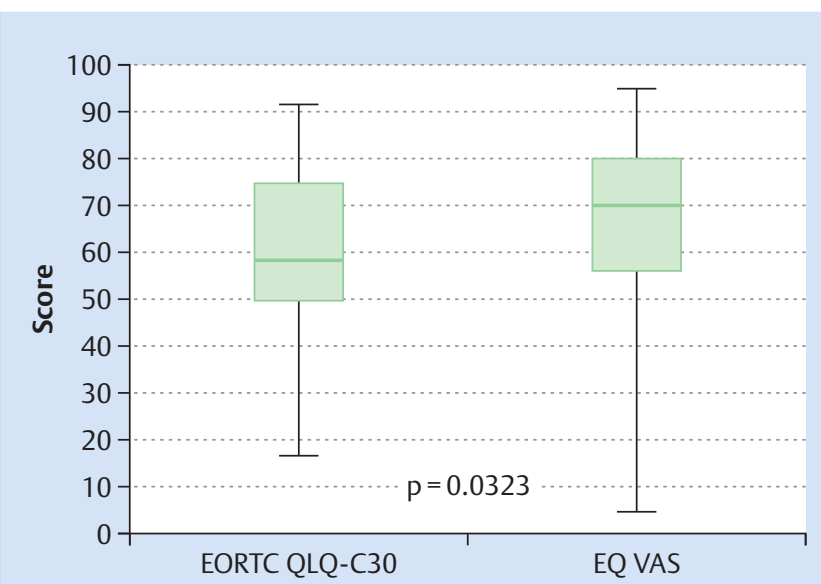

Fig. 3 Box plot comparing quality of life as determined by the EQ VAS and the EORTC QLQ-C30 questionnaires.

breath" ( +20.5 and +21.3 , respectively). The average score for overall state of health was $16.3 \%$ lower for the cohort of breast patients compared to the general female population and $16.2 \%$ lower compared to the reference group of the same age.

\section{Discussion}

This study describes the health-related quality of life of breast cancer patients with metastatic disease or receiving adjuvant treatment at a time when they were receiving therapy on an outpatient basis. Their state of health was found to be significantly poorer than that of the general population. Significantly, however, the study found that results differed depending on the questionnaire used. Although all questionnaires were completed by all patients at the same time (i.e. patients perceived their quality of life as the same across all questionnaires), there were significant differences in the depiction of the level of stress according to the tool used to survey patients. Depending on the survey tool used, quality of life and stress levels were depicted with varying degrees of intensity and with different symptoms, indicating that the results of different surveys need to be considered much more carefully. Although it is known that different survey tools give a different weight to different parameters (pain, physical condition, psychological condition, vegetative functions, etc.), too little consideration has been given to the fact that this results in different perceptions of patients' health. As monitoring of quality of life and other patient-related endpoints is used to assess the efficacy of therapeutic interventions, these differences between survey tools are clinically relevant. The EQ-5D-5L questionnaire identified pain and anxiety or depression as the main stressors. The EORTC QLQ-BR23 breast module pointed to relatively high

Table 2 Results for the EORTC QLQ-C30 and the EORTC QLQ-BR23.

\begin{tabular}{|c|c|c|c|c|c|}
\hline Scale & $\begin{array}{l}\text { Number of } \\
\text { questions (items) } \\
\text { EORTC QLQ-C30, V.3 }\end{array}$ & $\begin{array}{l}\text { Pooled score: } \\
\text { mean (SD) } \\
n=74\end{array}$ & $\begin{array}{l}\text { Score metastatic } \\
\text { disease: mean (SD) } \\
n=42\end{array}$ & $\begin{array}{l}\text { Score adjuvant: } \\
\text { mean (SD) } \\
\mathbf{n}=32\end{array}$ & $\begin{array}{l}\mathrm{p} \text {-value }(\alpha=0.05) \\
\text { Score metastatic } \\
\text { disease vs. adjuvant }\end{array}$ \\
\hline \multicolumn{6}{|l|}{ Functional scales } \\
\hline - Physical resilience* & $5(1-5)$ & $72.9(22.1)$ & $71.3(23.1)$ & $74.8(21.0)$ & 0.504 \\
\hline $\begin{array}{l}\text { Resilience at work and during } \\
\text { leisure time activities* }\end{array}$ & $2(6-7)$ & $59.4(32.5)$ & $62.6(33.2)$ & $55.6(31.7)$ & 0.363 \\
\hline Emotional resilience* & $4(21-24)$ & $63.6(24.7)$ & $65.5(25.2)$ & $61.4(24.4)$ & 0.707 \\
\hline - Cognitive resilience* & $2(20,25)$ & $75.4(26.2)$ & $71.7(36.7)$ & $78.4(25.7)$ & 0.381 \\
\hline Social resilience* & $2(26,27)$ & $61.4(32.4)$ & $60.4(30.5)$ & $62.6(35.0)$ & 0.774 \\
\hline \multicolumn{6}{|l|}{ Symptom scales } \\
\hline - Tiredness & $3(10,12,18)$ & $44.4(26.3)$ & $42.4(29.5)$ & $47.0(21.6)$ & 0.460 \\
\hline - Nausea/vomiting & $2(14,15)$ & $7.0(13.3)$ & $8.3(15.6)$ & $5.9(11.3)$ & 0.465 \\
\hline Pain & $2(9,19)$ & $32.3(32.4)$ & $34.4(31.5)$ & $30.6(33.4)$ & 0.618 \\
\hline - Shortness of breath & $1(8)$ & $27.7(28.6)$ & $23.0(27.0)$ & $33.3(29.8)$ & 0.124 \\
\hline - Sleep disturbance & $1(11)$ & $39.8(33.0)$ & $42.6(36.2)$ & $36.6(29.0)$ & 0.445 \\
\hline - Lack of appetite & $1(13)$ & $18.7(26.4)$ & $15.7(23.2)$ & $22.0(29.6)$ & 0.308 \\
\hline - Constipation & $1(16)$ & $10.8(24.7)$ & $11.7(27.5)$ & $9.7(21.4)$ & 0.735 \\
\hline D Diarrhea & $1(17)$ & $20.6(33.6)$ & $15.3(25.6)$ & $26.9(40.8)$ & 0.139 \\
\hline - Financial impact of disease & $1(28)$ & $23.5(31.9)$ & $19.8(29.9)$ & $28.2(34.2)$ & 0.269 \\
\hline - Overall state of health* & $2(29,30)$ & $58.2(21.0)$ & $57.4(22.0)$ & $59.0(20.0)$ & 0.748 \\
\hline Scale & $\begin{array}{l}\text { Number of } \\
\text { questions (items), } \\
\text { breast module BR23 }\end{array}$ & $\begin{array}{l}\text { Score: mean } \\
\text { (SD) }\end{array}$ & & & \\
\hline \multicolumn{6}{|l|}{ Functional scales } \\
\hline - Perception of own body & $4(9-12)$ & $69.4(30.1)$ & $62.6(34.1)$ & $69.7(24.6)$ & 0.323 \\
\hline Sexual activity* & $2(14,15)$ & $76.6(23.4)$ & $79.2(23.2)$ & $73.5(23.7)$ & 0.303 \\
\hline Enjoyment of sexual activity* & $1(16)$ & $43.5(25.5)$ & $36.7(10.5)$ & $48.7(32.2)$ & 0.026 \\
\hline - Concerns about future state of health & $1(13)$ & $44.9(31.2)$ & $46.8(32.8)$ & $42.7(29.6)$ & 0.580 \\
\hline \multicolumn{6}{|l|}{ Symptom scales } \\
\hline Side-effects of therapy & $7(1-4,6-8)$ & $27.7(18.6)$ & $29.6(18.9)$ & $25.9(18.8)$ & 0.406 \\
\hline Symptoms in the breast & $4(20-23)$ & $15.3(17.8)$ & $13.3(19.0)$ & $17.7(16.3)$ & 0.298 \\
\hline Symptoms in arm/shoulder & $3(17-19)$ & $23.5(23.7)$ & $22.8(22.1)$ & $24.4(25.9)$ & 0.775 \\
\hline - Low mood because of hair loss & $1(5)$ & $35.4(35.8)$ & $43.1(40.4)$ & $26.7(31.6)$ & 0.215 \\
\hline
\end{tabular}

\footnotetext{
* Items are scaled from worst to best, with high scores representing a good QoL profile.
} 
Table 3 Health-related quality of life (EORTC QLQ C30) for the cohort of breast cancer patients compared to the average female population in Germany and to an average group of women aged 50-59 years (reference cohort) [38].

\begin{tabular}{|c|c|c|c|c|c|c|c|}
\hline Scale & $\begin{array}{l}\text { 1st Tübingen } \\
\text { cancer cohort } \\
\text { (pooled): mean } \\
\text { (SD), } n=74^{*}\end{array}$ & $\begin{array}{l}\text { 2nd cohort of } \\
\text { reference } \\
\text { women: mean } \\
\text { (SD), } n=1309\end{array}$ & $\begin{array}{l}\text { Difference } \\
\text { between } \\
\text { 1st and 2nd }\end{array}$ & $\begin{array}{l}\text { p-value } \\
(\alpha=0.05)\end{array}$ & $\begin{array}{l}\text { 3rd cohort of } \\
\text { reference women } \\
\text { aged 50-59 years: } \\
\text { mean (SD), } n=272\end{array}$ & $\begin{array}{l}\text { Difference } \\
\text { between } \\
\text { 1st and 3rd }\end{array}$ & $\begin{array}{l}\text { p-value } \\
(\alpha=0.05)\end{array}$ \\
\hline \multicolumn{8}{|l|}{ Functional scales } \\
\hline - Physical resilience & $72.9(22.1)$ & $91.5(15.5)$ & -18.6 & $<0.0001$ & $92.9(13.7)$ & -20 & $<0.0001$ \\
\hline $\begin{array}{l}\text { Resilience at work and } \\
\text { during leisure time }\end{array}$ & $59.4(32.5)$ & $89.9(20.6)$ & -30.5 & $<0.0001$ & $91.9(18.5)$ & -32.5 & $<0.0001$ \\
\hline - Emotional resilience & $63.6(24.7)$ & $83.2(19.3)$ & $-19,6$ & $<0.0001$ & $82.2(20.6)$ & -18.6 & $<0.0001$ \\
\hline - Cognitive resilience & $75.4(26.2)$ & $93.4(14.6)$ & -18 & $<0.0001$ & $94.5(13.4)$ & -19.1 & $<0.0001$ \\
\hline Social resilience & $61.4(32.4)$ & $93.3(17.1)$ & -31.9 & $<0.0001$ & $93.6(17.0)$ & -32.2 & $<0.0001$ \\
\hline \multicolumn{8}{|l|}{ Symptom scales } \\
\hline - Tiredness & $44.4(26.3)$ & $16.4(21.4)$ & 28 & $<0.0001$ & $15.6(21.1)$ & 28.8 & $<0.0001$ \\
\hline - Nausea/vomiting & $7.0(13.3)$ & $2.4(9.6)$ & 4,6 & $<0.0001$ & $1.6(7.9)$ & 5.4 & $<0.0001$ \\
\hline > Pain & $32.3(32.4)$ & $17.0(24.2)$ & 15.3 & $<0.0001$ & $16.0(24.7)$ & 16.3 & $<0.0001$ \\
\hline - Shortness of breath & $27.7(28.6)$ & $7.2(18.7)$ & 20,5 & $<0.0001$ & $6.4(17.9)$ & 21.3 & $<0.0001$ \\
\hline - Sleep disturbance & $39.8(33.0)$ & $13.0(23.6)$ & 26.8 & $<0.0001$ & $15.8(26.4)$ & 24 & $<0.0001$ \\
\hline - Lack of appetite & $18.7(26.4)$ & $4.2(13.9)$ & 14.5 & $<0.0001$ & $3.2(12.1)$ & 15.5 & $<0.0001$ \\
\hline - Constipation & $10.8(24.7)$ & $3.1(12.1)$ & 7,7 & $<0.0001$ & $2.9(12.5)$ & 7.9 & 0.0002 \\
\hline - Diarrhea & $20.6(33.6)$ & $2.9(12.7)$ & 17,7 & $<0.0001$ & $1.5(8.5)$ & 19.1 & $<0.0001$ \\
\hline - Financial impact & $23.5(31.9)$ & $4.8(16.3)$ & 18.7 & $<0.0001$ & $4.5(17.9)$ & 19 & $<0.0001$ \\
\hline Overall state of health & $58.2(21.0)$ & $74.5(19.4)$ & -16.3 & $<0.0001$ & $74.4(17.9)$ & -16.2 & $<0.0001$ \\
\hline
\end{tabular}

* Usable results for the EORTC questionnaire were available for 74 out of the total cohort of breast cancer patients $(n=96)$.

levels of stress caused by the side-effects of therapy and by the loss of hair in particular. In the cohort investigated in this study the EORTC QLQ-C30 questionnaire was found to be the instrument which reflected the self-reported quality of life of patients best and was most differentiated; in principle, the choice of questionnaire should depend on the problem being investigated. As the assessment of the multi-dimensional EORTC QLQ-C30 questionnaire showed, the quality of life of patients is need in of improvement in all areas and was significantly poorer than in the reference population. Given the therapeutic goal for patients with metastatic disease (prolonging survival times while providing the best quality of life possible) [12-14], the difference in quality of life between patients and the reference cohort is particularly relevant. There were significant deficits (at the level of the functional scales) in the areas "social resilience" and "work and leisure-related resilience", while at the level of the symptom scales differences in the symptoms "tiredness", "sleep disturbance" and "shortness of breath" were particularly pronounced. The overall state of health was rated lower by an average of 16.3 points on the scale compared to the score for the average population and 10.8 percent points lower compared to the reference group of the same age. Although the case numbers of the cohort were relatively small, the responses of patients using the EORTC questionnaire largely correspond to the results of other studies in both the functional scales and the symptom scales $[29,30]$, although these studies did not compare the scores for patients' quality of life with those of a reference population to demonstrate the level of stress experienced by patients. This study therefore emphasizes the necessity of measuring patient-related endpoints with different survey tools to permit a realistic assessment of patients' quality of life and to improve the quality of life of patients with metastatic disease. Continuous monitoring is also important for patients in the adjuvant setting who have a similarly low quality of life. Adjuvant chemotherapy is usually administered to patients with no evidence of metastatic disease fol- lowing surgical excision of the primary tumor but in whom metastatic disease cannot be ruled out $[39,40]$. At the same time the study emphasizes the importance of investigating subjective health variables across many different dimensions as the depictions of the patient's state of health depends on the respective survey tool. For this reason, the G-BA has suggested that to measure the quality of life in PRO surveys, both a generic and a specific questionnaire should be used. One of the strengths of this study is that it identified significant differences in the depiction of quality of life depending on the survey tool used. A limitation of this study was the low number of cases which did not show significent differences in quality of life between patients with metastatic disease and patients in the adjuvant setting. The expectation would be that patients with metastatic disease have a lower self-reported quality of life compared to patients receiving adjuvant therapy $[32,40]$. Studies which permit direct comparisons between the two groups of patients are needed. To improve the validity of surveys on health-related quality of life it would be useful to carry out analogous studies with larger patient cohorts to determine whether the differences between the depicted quality of life found in this study with different questionnaires might be related to the patient's disease status. Multi-center studies of patients with metastatic disease would be particularly useful to determine to what extent the degree and site of metastasis and the therapy affect the patient-reported quality of life. In this study all patients of the cohort were surveyed during therapy when they were receiving a therapeutic intervention and the timepoint of the survey was therefore probably not a limiting factor. However, because of the length of the survey and because patients were not permitted to take the questionnaire home to complete it there, not all patients completed all sections of the survey. It is possible that the type and form of therapy may have acted as a bias, as it was not possible to take into account whether patients were receiving only chemotherapy at the time of the survey or a combination of chemotherapy and targeted therapy 
or only targeted therapy. Here too, larger studies will be necessary to generate subgroups with a statistically valid size.

\section{Conclusion}

Despite therapeutic advances, the health-related quality of life of breast cancer patients with metastatic disease or receiving adjuvant therapy could be improved even further compared to that of the average population. The study highlights the need to continuously monitor the quality of life of patients in a palliative setting to promote the therapeutic goal - which is to ensure that patients survive as long as possible with as few symptoms as possible. The choice of questionnaire used to monitor the patient affects the depiction of the patient's quality of life.

\section{Compliance with Ethical Guidelines}

All investigations of people were carried out with the approval of the appropriate ethics committee and complied with national law and with the 1975 Declaration of Helsinki (in its current revised version). Informed consent was obtained from all patients.

\section{Conflict of Interest \\ $\nabla$}

The authors state that there is no conflict of interest.

\section{Affiliations}

${ }^{1}$ Abteilung für Allgemeine Frauenheilkunde und Geburtshilfe, Universitätsklinikum Heidelberg, Heidelberg, Germany

2 Department für Frauengesundheit, Universitätsklinikum Tübingen, Tübingen, Germany

${ }^{3}$ Forschungsinstitut für Frauengesundheit, Universitätsklinikum Tübingen, Tübingen, Germany

${ }^{4}$ Stabsstelle Sozialmedizin, Universitätsklinikum Tübingen, Tübingen, Germany

5 Frauenklinik, Universitätsklinikum Erlangen, Erlangen, Germany

${ }^{6}$ Studiendekanat, Medizinische Fakultät, Universität Tübingen, Tübingen, Germany

\section{References}

1 Rhiem K, Schmutzler RK. Risikofaktoren und Prävention des Mammakarzinoms. Onkologe 2015; 21: 202-210

2 RKI (Robert Koch-Institut). Krebs in Deutschland 2009/2010. Berlin 2015. Online: http://www.krebsdaten.de/Krebs/DE/Content/ Publikationen/Krebs_in_Deutschland/kid_2015/krebs_in_deutschland 2015.pdf?_blob=publicationFile; last access: 01.04.2016

3 RKI (Robert Koch-Institut); Zentrum für Krebsregisterdaten. Brustkrebs (Mammakarzinom). Online: http://www.krebsdaten.de/Krebs/DE/ Content/Krebsarten/Brustkrebs/brustkrebs_node.html; last access: 10.03.2016

4 Gondos A, Bray F, Hakulinen Tet al. Trends in cancer survival in 11 European populations from 1990 to 2009: a model-based analysis. Ann Oncol 2009; 20: 564-573

5 Kunze U. Mammakarzinom: Epidemiologie und Risikofaktoren. J Gastroenterol Hepatol Erkr 2011; 9: 38-40

6 Cady B. Local therapy and survival in breast cancer. N Engl J Med 2007; 357: 1051-1052; author reply 1052

7 Heil J, Gondos A, Rauch G et al. Outcome analysis of patients with primary breast cancer initially treated at a certified academic breast unit. Breast 2012; 21: 303-308

8 Jemal A, Siegel R, Xu J et al. Cancer statistics, 2010. CA Cancer J Clin 2010; 60: 277-300

9 MacMahon B. Epidemiology and the causes of breast cancer. Int J Cancer 2006; 118: 2373-2378

10 De Grève J, Sermijn E, De Brakeleer $S$ et al. Hereditary breast cancer: from bench to bedside. Curr Opin Oncol 2008; 20: 605-613
11 Hamilton R. Genetics: breast cancer as an exemplar. Nurs Clin North Am 2009; 44: 327-338

12 Schneeweiss A, Ruckhäberle E, Huober J. Chemotherapie des metastasierten Mammakarzinoms - ein Anachronismus in der Ära der personalisierten, zielgerichteten onkologischen Therapie? Geburtsh Frauenheilk 2015; 75: 574-583

13 Dufresne A, Pivot X, Tournigand C et al. Impact of chemotherapy beyond the first line in patients with metastatic breast cancer. Breast Cancer Res Treat 2008; 107: 275-279

14 Cortés J, Baselga J, Im YH et al. Health-related quality-of-life assessment in CLEOPATRA, a phase III study combining pertuzumab with trastuzumab and docetaxel in metastatic breast cancer. Ann Oncol 2013; 24: 2630-2635

15 Martino M, Ballestrero A, Zambelli A et al. Long-term survival in patients with metastatic breast cancer receiving intensified chemotherapy and stem cell rescue: data from the Italian registry. Bone Marrow Transplant 2015; 48: 414-418

16 Jackisch $C$. Metastasiertes Mammakarzinom: Längeres und besseres Überleben. Dtsch Arztebl 2014; 111: 18-23

17 Cetin K, Christiansen CF, Sværke C et al. Survival in patients with breast cancer with bone metastasis: a Danish population-based cohort study on the prognostic impact of initial stage of disease at breast cancer diagnosis and length of the bone metastasis-free interval. BMJ Open 2015; 5: e007702

18 Ahn SG, Lee HM, Cho SH et al. Prognostic factors for patients with boneonly metastasis in breast cancer. Yonsei Med J 2013; 54: 1168-1177

19 RKI (Robert Koch-Institut). Gesundheitsbezogene Lebensqualität. Online: http://www.rki.de/DE/Content/Gesundheitsmonitoring/ Gesundheitsberichterstattung/GesundAZ/Content/G/Gesbez Lebensqualitaet/Gesbez_Lebensqualitaet.html; last access: 10.01.2016

20 Radoschewski M. Gesundheitsbezogene Lebensqualität - Konzepte und Maße. Bundesgesundheitsbl Gesundheitsforschung Gesundheitsschutz 2000; 43: 165-189

21 Kemmler G, Holzner B, Kopp M et al. Comparison of two quality-of-life instruments for cancer patients: the functional assessment of cancer therapy-general and the European Organization for Research and Treatment of Cancer Quality of Life Questionnaire-C30. J Clin Oncol 1999; 17: 2932-2940

22 Stephens C, Alpass F, Baars $M$ et al. SF-36v2 norms for New Zealanders aged 55-69 years. N Z Med J 2010; 123: 1-11

23 Laguardia J, Campos MR, Travassos CM et al. Psychometric evaluation of the SF-36 (v.2) questionnaire in a probability sample of Brazilian households: results of the survey Pesquisa Dimensoes Sociais das Desigualdades (PDSD), Brazil, 2008. Health Qual Life Outcomes 2011; 9: 61

24 Ellert U, Kurth BM. Gesundheitsbezogene Lebensqualität bei Erwachsenen in Deutschland. Ergebnisse der Studie zur Gesundheit Erwachsener in Deutschland (DEGS1). Bundesgesundheitsbl Gesundheitsforschung Gesundheitsschutz 2013; 56: 643-649

25 IQWiG (Institut für Qualität und Wirtschaftlichkeit im Gesundheitswesen). Allgemeine Methoden, 2008, S.31. Online: https://www. iqwig.de/download/IQWiG_Methoden_Version_3_0.pdf; last access: 09.01.2016

26 G-BA (Gemeinsamer Bundesausschuss). Verfahrensordnung des Gemeinsamen Bundesausschusses, Stand: 21.06.2012, S.30. Online: https://www.g-ba.de/downloads/62-492-634/VerfO_2012-06-21.pdf; last access: 09.01.2016

27 Perry S, Kowalski TL, Chang CH. Quality of life assessment in women with breast cancer: benefits, acceptability and utilization. Health Qual Life Outcomes 2007; 5: 24

28 Koch L, Jansen L, Herrmann A et al. Quality of life in long-term breast cancer survivors - a 10-year longitudinal population-based study. Acta Oncol 2013; 52: 1119-1128

29 Alzabaidey FJ. Quality of life assessment for patients with breast cancer receiving adjuvant therapy. J Cancer Sci Ther 2012; 4: 051-055

30 Karamouzis MV, Ioannidis G, Rigatos G. Quality of life in metastatic breast cancer patients under chemotherapy or supportive care: a single-institution comparative study. Eur J Cancer Care (Engl) 2007; 16: 433-438

31 Kyrgidis A, Triaridis S, Kontos $K$ et al. Quality of life in breast cancer patients with bisphosphonate-related osteonecrosis of the jaws and patients with head and neck cancer: a comparative study using the EORTC QLQ-C30 and QLQ-HN35 questionnaires. Anticancer Res 2012; 32: 3527-3534 
32 Korpela J, Mali P, Kaljonen A et al. Quality of life of patients with metastatic breast cancer treated with epirubicin and docetaxel. Int J Clin Med 2011; 2: 346-351

33 Aaronson NK, Ahmedzai S, Bergman B et al. The European Organization for Research and Treatment of Cancer QLQ-C30: a quality-of-life instrument for use in international clinical trials in oncology. J Natl Cancer I 1993; 85: 365-376

34 Nguyen J, Popovic M, Chow E et al. EORTC QLQ-BR23 and FACT-B for the assessment of quality of life in patients with breast cancer: a literature review. J Comp Eff Res 2015; 4: 157-166

35 Greiner W, Claes C, Busschbach JJ et al. Validating the EQ-5D with time trade off for the German population. Eur J Health Econ 2005; 6: 124130

36 EORTC data center. EORTC QLQ C-30 Scoring Manual. 3rd ed. Brussels: Eigenverlag; 2001. Online: https://www.google.de/url?sa=t\&rct= $j \& q=\& e s r c=s \&$ source $=$ web $\& c d=9 \&$ cad $=$ rja\&uact $=8 \&$ ved $=0$ ahUKEwj KuuycgqfKAhVIJw4KHWL7D2EQFghhMAg\&url=https\%3 A\%2 F\%2F wiki.nci.nih.gov\%2Fdownload\%2Fattachments\%2F167543767\% 2FEORTC_QLQ_C30\%2520_scoring_Manual.pdf\%3Fversion\%3D1\% 26modificationDate\%3D1412301929000\%26api\%3Dv2\&usg= AFQjCNH_ZiUk6ZwXzvdpwzWEjUTRNhhJcQ\&bvm=bv.111396085,bs. 1,d.bGQ; last access: 10.01.2016
37 Van Reenen M, Janssen B. EQ-5D-5L User Guide. Basic information and how to use the EQ-5D-5L instrument. 2015. Online: http://www. euroqol.org/fileadmin/user_upload/Documenten/PDF/Folders_Flyers/ EQ-5D-5L_UserGuide_2015.pdf; last access: 12.01.2016

38 Hinz A, Singer S, Brahler E. European reference values for the quality of life questionnaire EORTC QLQ-C30: results of a German investigation and a summarizing analysis of six European general population normative studies. Acta Oncol 2014; 53: 958-965

$39 \mathrm{NIH}$ National Cancer Institute. Adjuvant and neoadjuvant therapy for breast cancer. 2009. Online: http://www.cancer.gov/types/breast/ adjuvant-fact-sheet; last access: 01.02.2016

40 Bernhard J, Luo W, Ribi $K$ et al. Patient-reported outcomes with adjuvant exemestane versus tamoxifen in premenopausal women with early breast cancer undergoing ovarian suppression (TEXT and SOFT): a combined analysis of two phase 3 randomised trials. Lancet Oncol 2015; 16: 848-858 